\title{
Significados e Ressignificações do Letramento: desdobramentos de uma perspectiva sociocultural sobre a escrita
}

\author{
Ana Elisa Jacob*
}

Os estudos sobre Letramentos no Brasil, desde o início da década de 1990, vêm contribuindo para um debate mais esclarecedor e aprofundado do papel da escrita e seu desenvolvimento nas diferentes práticas sociais. Ao contrário do que supunham no momento emergencial dessas pesquisas, a escrita não desempenha sua função apenas em lugares ditos de prestígio e de forma autônoma, ela está presente e é constituída no cotidiano das pessoas, desempenhando diferentes papéis sociais, exercendo poder e influenciando na formação da identidade de um povo.

Partindo dessa percepção múltipla dos letramentos e de suas influências nos processos de ensino-aprendizagem e de Formação Docente é que o livro Significados e Ressignificações do Letramento: desdobramentos de uma perspectiva sociocultural sobre a escrita foi organizado pelas professoras Angela B. Kleiman (UNICAMP) e Juliana Alves de Assis (PUC-Minas). A obra retrata as temáticas atuais dos estudos sobre Letramentos, a partir da vertente sociocultural, marcando os vinte e cinco anos de pesquisa do grupo Letramento do Professor. Todos os capítulos do livro se reconhecem como pertencentes à Linguística Aplicada e tratam os diferentes objetos de pesquisa dos Letramentos de uma forma intermultidisciplinar, nas palavras de Angela B. Kleiman, uma vez que as práticas sociais de que procedem são da mesma natureza.

A obra está organizada em quatro partes, subdivididas em dezesseis capítulos, além da Apresentação, que nos fornece um estado da arte das pesquisas do grupo Letramento do Professor, e da Introdução, que traça um percurso histórico do desenvolvimento dos estudos, retoma os conceitos principais dos Novos Estudos sobre Letramento (NSL), e também aponta para novas possibilidades de pesquisa: o Letramento Acadêmico-Profissional e sua importância para o Letramento do Professor na Formação Inicial e Continuada.

A parte um, Interseções Disciplinares, dispõe de textos que evidenciam as possibilidades fronteiriças de abordar e investigar os diferentes objetos de estudo sobre Letramentos, recorrendo a uma diversidade de áreas confluentes com a

\footnotetext{
*Endereço eletrônico: ana.elisa.jacob@gmail.com
}

perspectiva sociocultural. Podemos constatar tal natureza híbrida dos estudos já no primeiro capítulo que compõe essa parte inicial, Representações Sociais e Letramentos, quando Juliana Alves Assis aproxima-se da Teoria das Representações Sociais, da Psicologia Social, para defender que todo projeto de ensino, bem como as práticas investigativas que se propõem a estudá-lo, não são neutros, ao contrário, são influenciados e determinados pelas representações sociais que os permeiam, condicionando, por conseguinte, seu desenvolvimento e sucesso.

No segundo capítulo, Linguagem $e$ Processos de Letramento: uma experiência formativa, Maria Angela Paulino Teixeira Lopes, a partir das contribuições de Vigotski, Volochinov e Bakhtin, com vista na reflexão de possibilidades para a Formação Inicial do professor, encaminha o leitor para a análise de um estudo longitudinal de Formação Inicial, guiando-o para o movimento histórico das ressignificações sobre leitura e compreensão de textos orais e escritos, considerando as mudanças no cenário científico, sobretudo, no que tange os estudos da linguagem como prática social. Ivoneide Bezerra de Araújo Santos Marques, por sua vez, no terceiro capítulo, Formação de Professores de Língua Portuguesa: projetos de Letramento, agência e empoderamento, aproxima-se da temática da Formação Continuada de Professores partindo da concepção de linguagem também bakhtiniana, além da Pedagogia Crítica e dos estudos da Nova Retórica. Defende, para esse debate, o ponto de vista dos Projetos de Letramento, os quais, segundo a autora, promovem a ampliação do letramento do professor e o coloca na posição de agente no desenvolvimento do processo de letramento do aluno, já que a linguagem é tomada como prática social e como ação nas diferentes esferas discursivas.

No quarto e último capítulo da primeira parte do livro, Olhares para encontros mediados pela escrita: uma proposta de reconfigurações conceituais e metodológicas, Mary Elizabeth Cerutti-Rizzatti, Suziane da S. Mossmann e Josa Coelho da Silva Irigoite investem na compreensão das formas de apropriação da escrita pelos alunos 
pertencentes a estratos de vulnerabilidade social, guiadas pelos postulados bakhtinianos $\mathrm{e}$ vigotskianos. Para esse fim, as autoras argumentam que, nos eventos de letramento, há o agenciamento dos interactantes quando eles se apoderam da palavra outra, sucedendo, portanto, trocas dialógicas e dialéticas no processo de apropriação da escrita pelos alunos, o que contribui para a constituição do outro e de si mesmo.

A parte dois do livro, Letramentos às Margens, adentra as regiões dos eventos de letramento dos estratos marginais da sociedade e evidencia as tensões insurgidas quando estreitados seus limites com as práticas validadas e imbuídas de poder institucional. Metodologicamente, os capítulos que compõem essa parte do livro são de cunho etnográfico. No primeiro capítulo, Multiletramentos, Interdições e Marginalidades, Angela B. Kleiman e Luanda Sito, assumem o propósito de investigar as estratégias de letramento acionadas por grupos marginalizados, principalmente, pela população negra, a fim de descrever os multiletramentos de sua cotidianidade e as subversões que lançam mão para se inserirem nos lugares dantes não circuláveis por ela, nas práticas de prestígio. As autoras, por conseguinte, inculcam a necessidade do conhecimento mais amplo da sociedade dos multiletramentos da marginalidade, defendendo-os no papel de objetos de estudo acessíveis e capitais para o ensinoaprendizado da escrita.

Subversão semelhante aos preceitos habituais educacionais sobre a escrita é vista na experiência relatada no segundo capítulo, Escrita e Autoria na Formação da Professora Indígena, dos autores Kátia Maria Rodrigues Gomes e Cosme Batista dos Santos. Um caso de formação de professoras indígenas Trukás evidenciou a possibilidade de reafirmação da identidade desse povo pela escrita minorizada. A produção de livros com as histórias do povo Truká pelas professoras revelou que o caminho pode ser a luta por uma educação intercultural para o povo indígena. A escrita sentida minorizada no cotidiano das professoras indígenas também o foi para as professoras de Língua Portuguesa que colaboraram com a pesquisa das autoras Simone Bueno Borges da Silva e Laureci Ferreira da Silva, no capítulo Etnografia e Autoetnografia na Formação dos Professores. Através das narrativas das professoras, revelou-se a profunda sensação de incapacidade em ensinar a ler e escrever nas múltiplas práticas sociais, visto que elas sentiam, cotidianamente, as lacunas desvitalizantes, a ausência do poder de ação, da própria formação profissional.

No capítulo Letramentos e Políticas Públicas: a família na escola, de Maria do Socorro Oliveira, a potencialidade do agir educacional foi retomada pela importância do estabelecimento de laços mais vigorosos entre as práticas de letramento escolar, familiar e comunitário além da articulação entre as políticas públicas e os projetos de letramento. A escrita, nesse processo de estreitamento de objetivos comuns da comunidade escolar, foi essencial, como destaca a autora, pois as investidas de aproximação se deram por suas práticas, pelos gêneros textuais variados, quando os trabalhos escolares passaram a ser orientados pelos interesses dos próprios alunos, bem como pela escuta e observação dos problemas da própria comunidade e da família, impactando, positivamente e diretamente, na aprendizagem dos alunos.

A parte três, Letramentos e Aprendizes, e a Parte Quatro, Letramento Profissional: formação de professores, voltam-se para questões mais específicas dos contextos de ensino e de aprendizagem, formais e informais, identificando-se quanto às abordagens linguístico-enunciativodiscursiva para análise dos dados. A parte três inicia-se com a relevante discussão proposta pelas autoras Luzia Bueno e Ermelinda Barricelli sobre o papel das prescrições educacionais na formação do professor e no tratamento dos diferentes objetos de ensino, no capítulo Letramento no Referencial Curricular Nacional para Educação Infantil (RCNEI). Nesse momento, as autoras discorrem sobre a análise feita dos RCNEI, em relação ao trabalho com a linguagem, amparadas pelas contribuições dos estudos da Ergonomia da Atividade ou Clínica da Atividade e do Interacionismo Sociodiscursivo. $\mathrm{Na}$ análise do documento, as autoras se deparam com um tratamento restritivo das questões dos letramentos no documento oficial, revelando a ausência da perspectiva plural das práticas sociais de que procedem, enfatizando um ponto de vista ideal dos usos da escrita. Assim também ocorre com o trabalho do professor, idealizam-no, partindo do pressuposto de que, para seu sucesso, é necessário se aproximar, cada vez mais, das prescrições dos RCNEI, que, por sua vez, se mostram autônomos das variadas realidades pedagógicas.

O segundo capítulo, Leitura: concepções, 
práticas e representações, de Adilson Ribeiro de Oliveria e Hejane de Oliveria Fonseca, disserta sobre a leitura como uma dimensão constituinte dos letramentos, pois, conforme os autores, é uma prática social engendrada pela cultura do escrito, que se embebe de valores sociais conforme a esfera de atividade em que se perfaz. Em um processo investigativo sobre as concepções de leitura de alunos de dois níveis de ensino, o Médio e o Superior, os autores discutem sobre as maneiras de ler e as influências socioculturais que auxiliam no processo de construção da própria singularidade leitora desses indivíduos, assim como, determinam os tipos de inserção e socialização no mundo da leitura. No último capítulo que compõe a terceira parte do livro, Práticas de Leitura e Escrita: Modos de dizer e atribuir identidades, dos autores Daniella Lopes Dias Ignácio Rodrigues, Gilda Maria R. Fonseca e João Batista Martins, discute-se a respeito da inserção dos alunos no ambiente acadêmico por meio da escrita. A discussão proposta, sob o ponto de vista dos Letramentos Acadêmicos, tem o intuito de verificar as estratégias linguísticas utilizadas por eles que revelam sua identidade ora como alunos, ora como estagiários, ora como profissionais.

A parte quatro que encerra a obra, Letramento Profissional: formação de professores, é composta por cinco capítulos. O primeiro deles, Vozes dos Estagiários: articulações entre práticas de letramento e construção de sentidos para a profissão docente, de Ana Lúcia Guedes-Pinto, por intermédio da análise de pequenos ensaios dos alunos estagiários do curso de Pedagogia, dispõe-se a investigar os recursos linguísticos utilizados que revelam o percurso autoral da escrita acadêmica e, de certo modo, influenciam na própria constituição profissional. Para essa análise, lançou-se mão da proposta discursiva de Bakhtin e Volochinov, que a amparou na visibilidade da voz do outro no discurso dos estagiários, de sua apropriação por eles, assim como, da composição da estética de suas escritas. O segundo capítulo, $O$ estágio supervisionado como prática de letramento acadêmico-profissional, de Carla Lynn Reichmann, sob a perspectiva teóricometodológica do Interacionismo Sociodiscursivo, acrescenta ao tema da Formação Inicial do Professor a importância de explorarmos a questão do letramento também no local de trabalho e não apenas na academia, portanto, o letramento acadêmico-profissional.

O terceiro capítulo, Das Práticas Discursivas às (Re) construções de Imagens
Docentes: as representações sobre o trabalho do professor de português, de Janaína Zaidan Bicalho Fonseca, Maria Alzira Leite e Karine Correia dos Santos Oliveira, com o auxílio metodológico da Entrevista Semiestruturada Focalizada, da Instrução ao Sósia, e da Autoconfrontação Simples, além da teoria das Representações Sociais, da Psicologia Social, objetivou refletir sobre o processo histórico de mudança das representações sociais que envolvem o papel do professor, a partir de um processo interativo que fez emergir a memória e o saber docente.

O quarto capítulo, (Des) Caminhos para o Letramento do Professor no Espaço da Formação Docente, de Marília Curado Valsechi e Súlvia Letícia Matievicz Pereira, nos incute a necessidade do estabelecimento de vínculos mais estreitos entre a esfera acadêmica e profissional nos processos de formação inicial e continuada do professor. Com esse intuito, as autoras visam, nos contextos investigados, verificar se há espaços privilegiados de interseção entre saberes e práticas de tais esferas sociais. A defesa do capítulo está no encurtamento da distância entre o letramento acadêmico e as práticas no local de trabalho, sendo os espaços de formação, estágio supervisionado ou programas de formação continuada, essenciais para garantir esse processo, já que eles têm o potencial de ser o entrelugar socioprofissional.

$\mathrm{O}$ quinto e último capítulo que encerra a parte quatro e também o livro, Agência e Demanda na Formação Continuada de Professores: possíveis caminhos para construção de conhecimento em eventos formativos, de Carolina Assis Dias Vianna e Paula Baracat De Grande, aborda a questão da Formação Continuada do Professor a partir de duas experiências: de reuniões de trabalho pedagógico coletivo, em uma escola pública, e de um projeto de assessoria pedagógica de editora. Nesse percurso, as autoras demostram que os espaços de formação abrangem outros espaços-tempos distintos dos considerados oficiais, além de levarem a uma reflexão sobre os poderes exercidos por certos sujeitos de certas esferas sociais em todo processo de formação, os quais legitimam os saberes.

A relevância dessa coletânea para o campo da Linguística Aplicada, e para os demais que estabelecem com ela uma relação de trocas profícuas para os estudos sobre a escrita como prática social e seu desenvolvimento, é notória, pois constata-se possibilidades de abordar esse tema, de torná-lo objeto de pesquisa e, consequentemente, de 
ensino-aprendizagem. A temática Formação de Professor é ampliada e compreendida em suas particularidades, ação possível pelas microanálises etnográficas que vão ao encontro dos detalhes empíricos e das destoantes realidades educacionais e de formação. Através de propostas desse tipo, os multiletramentos são cada vez mais visíveis e confirmam a necessidade de seus eventos e práticas tornarem-se também objetos de ensino, além daqueles já consolidados nas orientações educacionais e nas práticas educacionais.

Direta ou indiretamente, nos capítulos desenvolvidos, aponta-se caminhos possíveis para a Formação Docente: a aproximação do Letramento Acadêmico do Letramento Profissional e a mudança de direção dos conhecimentos eleitos a serem ensinados, não mais de cima para baixo, mas na articulação entre a demanda da prática escolar, das práticas sociais que a circundam e das teorias. Inquestionavelmente, o conjunto da obra enriquece o repertório de pesquisadores interessados pela Formação Docente e por aqueles que queiram traçar novos e diversos caminhos em suas próprias práticas educacionais.

\section{Referência}

KLEIMAN, A. B \& ASSIS, J. A. (Orgs). Significados e Ressignificações do Letramento: desdobramentos de uma perspectiva sociocultural sobre a escrita. $1^{a}$ edição. Campinas: Mercado de Letras, 2016.

\section{Sobre a autora}

Ana Elisa Jacob: Doutoranda em Educação, linguagens e processos interativos pela Universidade São Francisco - Itatiba/SP (bolsista Capes). Mestre em Linguística Aplicada e Estudos da Linguagem pela PUC-SP (bolsista CNPq). Membro dos grupos ALTER-LEGE-USF/CNPq e ALTER-Age/USP. Desenvolve pesquisas relacionadas ao ensino-aprendizado de gêneros textuais sob as óticas do Interacionismo Sociodiscursivo e dos Letramentos Sociais.

Recebido em setembro 2017.

Aprovado em janeiro 2018. 